\title{
The Application of Fuzzy Comprehensive Evaluation Method in Financial Early Warning of Real Estate Enterprises
}

\author{
Jingyi Cai \\ WuHan Polytechnic, WuHan, HuBei 430074, China \\ caidouhule@126.com
}

\begin{abstract}
Keywords: Real estate enterprises; Financial crisis; Fuzzy comprehensive evaluation method; Financial early warning
\end{abstract}

\begin{abstract}
With the accelerated pace of global economic integration, Chinese enterprises will face more intense market competition while welcoming the opportunities for development. The research of enterprise financial early-warning is a research topic which is widely concerned. With the continuous changes of the domestic economic situation and the introduction of the relevant policies of the national real estate, various uncertain factors in the operation of the real estate enterprises continue to increase, and the financial wind is also increasing. The financial risk of the real estate enterprise is fuzzy and complex, which is influenced by many factors such as finance and non-finance. In order to improve the effectiveness of financial early warning system, based on the micro group of real estate enterprises, based on the financial early warning system with financial indicators as the main body, this paper applies fuzzy comprehensive evaluation method to build a financial early-warning model of real estate enterprises. According to the characteristics of real estate enterprises, non-financial indicators are selected to study the non-financial indicators that affect the financial early warning of real estate enterprises. This will be of great benefit to the construction of the financial early-warning system for the real estate enterprises.
\end{abstract}

\section{Introduction}

With the continuous change of the domestic economic situation and the introduction of the national real estate related policies, various uncertain factors in the real estate enterprise are increasing. In order to ensure the steady and healthy development of the real estate market in 2011, the state put forward a series of policies such as "eight countries" [1-2]. Under the influence of domestic macro policy control and tightened financial policy, real estate enterprises are facing increasing financial risk when they are faced with shrinking market volume and rising cost. If the financial risk can not be effectively early-warning and dissolving, the financial crisis caused by this may endanger the life of the real estate enterprise.

Financial risk is fuzzy and complex, which is influenced by many factors such as finance and non-finance. The early warning model which is based on the financial index can not predict the financial risk of the enterprise. How to build a scientific and effective financial early-warning system has become a real problem to be solved in real estate enterprises [3-4]. If there is a potential crisis in the real estate business, financial risk early warning system to capture the financial management of the enterprises in various management mistakes, which will improve the anti-risk ability of enterprises and competitiveness to reduce financial losses and promote the healthy and sustainable development of enterprises [5]. Therefore, based on the current real estate enterprise financial risk increase, has the important practical significance of financial early-warning system and comprehensive research on how to construct the dynamic financial indicators as the basis, so as to make the real estate enterprises to effectively prevent risks in the changing social environment, improve management efficiency.

\section{The basic theory of fuzzy comprehensive evaluation method}

Fuzzy evaluation is based on the nonlinear characteristics of the evaluation process. It uses the fuzzy operation rule in fuzzy mathematics to quantify and integrate the nonlinear evaluation domain, 
so as to get a comparable quantitative evaluation process. Fuzzy mathematics was founded in 60 s of this century by Professor L. A. Zadeh [6]. It is a judgement model and method designed for a large number of economic phenomena in the real world, which has been continuously evolved by experts in practice.

The basic idea of fuzzy set theory is to admit the fuzziness in the development of things. It is believed that the objects involved in the discussion belong to a certain group rather than a sudden change [7-8]. In this way, the concept of absolute belonging is transformed into a relative concept. When discriminating, whether or not a set of discriminant objects belongs to a set becomes the degree of membership of a discriminant object to a set.

Given a domain $\mathrm{U}$, all the subsets in $\mathrm{U}$ are recorded as $P(U)$, that is:

$$
P(U)=\{A \subseteq U\}
$$

An exact concept, its extension is an ordinary set. Set this set to be A, then $\forall u \in U, u \in A$ or $u \notin A$, and the two must live only one.

A set of A by its characteristic function when describing:

$$
\begin{aligned}
& f_{A}: U \rightarrow\{0,1\} \\
& u \rightarrow f_{A}(u)=\left\{\begin{array}{l}
1, u \in A \\
0, u \notin A
\end{array}\right.
\end{aligned}
$$

For the finite field $U=\left\{u_{1}, u_{2}, \ldots u_{m}\right\}, \quad \mathrm{V}=\left\{V_{1}, V_{2}, \ldots V_{n}\right\}$, then the membership function $u_{R}(u, v)$ of the fuzzy relation $\underline{R}$ of $\mathrm{U}$ to $\mathrm{V}$ can be expressed as $m \times n$ order fuzzy matrix $R$, namely:

$$
\underline{R}=R=\left(r_{i j}\right)_{m \times n}
$$

Among $r_{i j}=R\left(u_{i}, v_{i}\right) \in[0,1]$ indicates the degree of correlation between $\left(u_{i}, v_{i}\right)$ and fuzzy relation $\underline{R}$.

Because of the existence of $\underline{R}=R$, the operation of fuzzy relation can be carried out entirely through the fuzzy matrix. The fuzzy matrix is more intuitionistic and easy to operate. In practical application, the fuzzy relation is always transformed into a fuzzy matrix.

\section{Construction of financial early-warning system for real estate enterprises}

The selection of early warning indicators is the first link of financial early-warning. Index selection starts with various factors that affect the financial activities of real estate enterprises, analyzes the specific contents of each factor, and classifies indicators according to the characteristics of the real estate industry [9]. When choosing indicators, we should consider the breadth of coverage as far as possible, while taking into account the qualitative indicators for quantitative analysis, so as to improve the operability of financial risk early warning system [10]. 


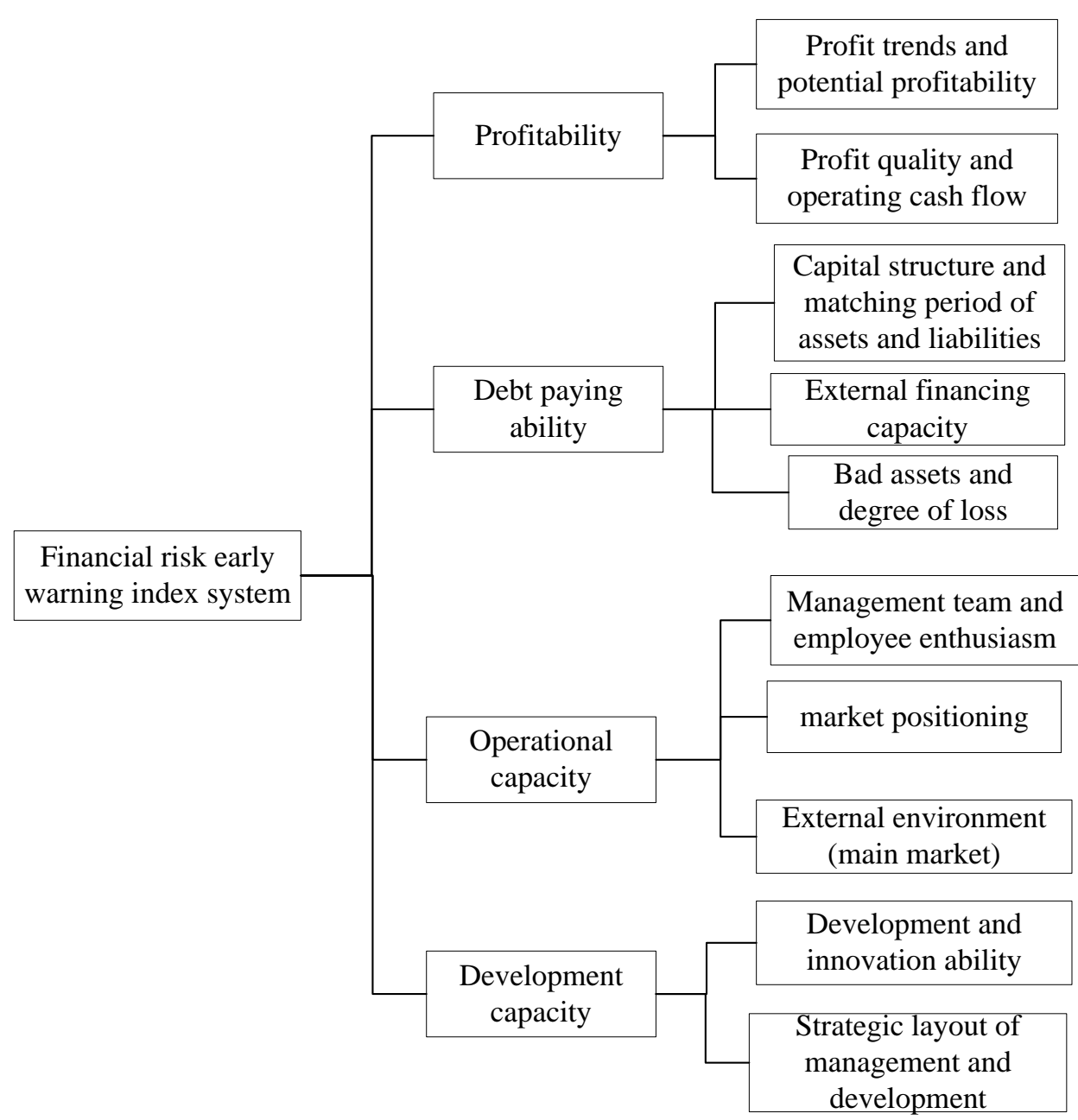

Figure 1. Financial risk early warning index system diagram

According to the design idea of the evaluation index system combined with the above analysis of financial risk and combining the characteristics of the real estate industry, this paper divides the non-financial index system into five aspects: profitability, debt paying ability, operation capacity, development capacity and internal control. The specific structure is shown in figure 1.

\section{Financial early-warning of real estate enterprises based on fuzzy comprehensive evaluation}

The non-financial index of the real estate enterprise is a multi-level complex system. The multilevel nature of these evaluation indicators and the fuzziness of evaluation factors make the non-financial indicators subjective in terms of attributes and constraints relatively large. It is difficult to give accurate decision information with classical mathematical methods and models. Multi-level fuzzy comprehensive evaluation method can play a good role in evaluating non-financial early warning. It can not only take account of the hierarchy of evaluation objects, but also make the fuzziness of evaluation factors manifest [11-12]. Multi-level fuzzy comprehensive evaluation is to first classify various factors of a thing to be evaluated according to its attributes, and divide them into several major factors. Then we conduct a comprehensive evaluation of each factor, and finally make a comprehensive evaluation of the results of primary evaluation. It is introduced into the financial early-warning system of real estate enterprises, financial risk factors can be complex real estate enterprises were divided into different levels, so that complex objects are difficult to quantify the decomposition for comparison a number of small range, operational early warning model of real estate enterprises increased the non-financial index. Multilevel fuzzy comprehensive evaluation process:

The set of fuzzy evaluation grade is determined.

The financial security situation of the enterprise is divided into 5 levels, which are very safe, safe, general, dangerous and dangerous. Therefore, the grade value of fuzzy evaluation is as follows: 
$V=\left\{V_{1}, V_{2}, V_{3}, V_{4}, V_{5}\right\}=\{$ very safe, safe, general, dangerous, very dangerous $\}$

Evaluation set assignment, $u=\{10,8,6,4,2\}$.

Table 1 Grade division of financial risk early warning evaluation

\begin{tabular}{|c|c|c|c|c|c|}
\hline Risk grade & V1 & V2 & V3 & V4 & V5 \\
\hline $\begin{array}{c}\text { Risk scoring } \\
\text { interval distribution }\end{array}$ & $(7,9)$ & $(6,8)$ & $(3,5)$ & $(1,3)$ & $(0,1)$ \\
\hline Risk level & very safe & safe & general & dangerous & very dangerous \\
\hline
\end{tabular}

Establish a set of factors.

The set of factors is a set of pre-selected indicators that reflect the targets of the evaluation. This refers to the collection of non-financial indicators in the financial early-warning system of real estate enterprises.

Factor set: $A=\left\{A_{1}, A_{2}, A_{3}, A_{4}, A_{5}\right\}=\{$ profitability, solvency, operational ability, ability, internal control $\}$

Single factor fuzzy evaluation.

Using the analytic hierarchy process (AHP) to empower each factor index, 11 experts are used to evaluate the financial situation of a company according to the value of the evaluation index.

Table 2 Comprehensive evaluation results

\begin{tabular}{|c|c|c|c|c|c|c|}
\hline \multicolumn{6}{|c|}{ Individual evaluation } & \multirow{2}{*}{$\begin{array}{c}\text { General } \\
\text { evaluation }\end{array}$} \\
\hline Sub index & Profitability & Solvency & $\begin{array}{l}\text { Operational } \\
\text { capacity }\end{array}$ & $\begin{array}{c}\text { Development } \\
\text { capacity }\end{array}$ & $\begin{array}{c}\text { Internal } \\
\text { control } \\
\text { capability }\end{array}$ & \\
\hline \begin{tabular}{|c|}
$\begin{array}{c}\text { Evaluation } \\
\text { score }\end{array}$ \\
\end{tabular} & 6.1 & 6.9 & 7.8 & 5.6 & 7.6 & 6.6 \\
\hline Risk grade & safe & safe & safe & general & safe & safe \\
\hline $\begin{array}{l}\text { Index } \\
\text { weight }\end{array}$ & 0.2 & 0.1 & 0.17 & 0.1 & 0.11 & \\
\hline
\end{tabular}

Comprehensive evaluation results.

The results of the comprehensive evaluation are obtained by combining the weights of each individual risk assessment and the corresponding indexes, as shown in table 2.

\section{Summary}

The results of quantitative analysis of financial indicators and qualitative analysis of non-financial indicators will make the results more true and reasonable. After the multilevel fuzzy comprehensive evaluation of the non-financial indicators of the company, it can be judged that it is in a state of security at present. Of course, the final evaluation of the company's financial status should be fully combined with quantitative analysis based financial indicators evaluation, and non-financial index evaluation methods should be a useful supplement to the traditional financial indicators early warning system. The dynamic comprehensive financial early-warning evaluation system based on 
the financial and non-financial indicators of the real estate enterprises will improve the risk management level of the enterprise.

\section{References}

[1] Mei J. The Application of Fuzzy Comprehensive Evaluation Method in the Selection of Enterprise Transportation Services[C]// Pulsed Power Conference (PPC), 2015 IEEE. IEEE, 2014.

[2] Qin Z, Wei X, Meng L. The financial evaluation research of real estate enterprise based on the fuzzy comprehensive evaluation method[C]// International Conference on Social Science, Education Management and Sports Education. 2015.

[3] Li M A, Zhang P. Application of Nonlinear Fuzzy Comprehensive Evaluation Method in Real Estate Investment Risk Analysis[J]. Construction Economy, 2014, 130:A15424-A15424.

[4] Shen H, Liu J, Cao Z, et al. Application of fuzzy comprehensive evaluation to early-warning assessment of ecological security: A case study in Weichang County of Hebei Province[J]. 2015, 36(6).

[5] He D, Shuai J. The Application of Fuzzy Comprehensive Evaluation Method for the Evaluation Enterprise Training Effectiveness[C]// International Conference on Computational Intelligence and Security. IEEE, 2014:329-333.

[6] Li L, Ma J, Zhan X. The development and application of cycle economic early warning system based on fuzzy comprehensive evaluation[J]. International Journal of Applied Decision Sciences, 2017, 10(1):1.

[7] Chen W, Ye H, Yun J. Risk Early Warning and Control of Rail Transportation Based on Fuzzy Comprehensive Evaluation Method in Wuhan City[J]. 2016.

[8] Wang J, He B, Jiang S. Application of AHP-FUZZY comprehensive evaluation method on the evaluation of enterprises' logistics outsourcing risks[J]. Metallurgical \& Mining Industry, 2015.

[9] Zhang Q, He D. The application of analytic hierarchy process and fuzzy comprehensive evaluation method for the evaluation of enterprise training effectiveness[J]. International Journal of Computational Science \& Engineering, 2017, 14(2):126.

[10] Xue L, Shen Y N, Zhi-Xing L U. Application of Fuzzy Comprehensive Evaluation Method in the Acceptance Evaluation of Science and Technology Project[J]. Computer Systems \& Applications, 2017.

[11] Hua J, Yuming B O, Chen Z, et al. An Improved Comprehensive Evaluation Method of Real Estate Market Based on Fuzzy Weight[J]. Journal of University of Jinan, 2014.

[12] Yang X, Yang W N, Liu H H, et al. The application of fuzzy comprehensive evaluation in risk assessment of debris flows in Yingxiu-Tiger Mouth Zone[J]. International Journal of Earth Sciences \& Engineering, 2014, 7(6):2126-2134. 